\title{
The Dichotomy in the Preinvasive Neoplasia to Invasive Carcinoma Sequence in the Pancreas: Differential Expression of MUC1 and MUC2 Supports the Existence of Two Separate Pathways of Carcinogenesis
}

\author{
N. Volkan Adsay, M.D., Kambiz Merati, M.D., Aleodor Andea, M.D., Fazlul Sarkar, Ph.D, \\ Ralph H. Hruban, M.D., Robb E. Wilentz, M.D., Micheal Goggins, M.D., \\ Christine Iocobuzio-Donahue, M.D., Daniel S. Longnecker, M.D., David S. Klimstra, M.D. \\ Departments of Pathology, Karmanos Cancer Institute (NVA, KM, AA, FS) and Wayne State University, \\ Detroit, Michigan; The Johns Hopkins University Hospital (RHH, REW, MG, CI-D), Baltimore, Maryland; \\ Dartmouth Medical School (DSL), Hanover, New Hampshire; Memorial Sloan-Kettering Cancer Center \\ (DSK), New York, New York
}

Emerging evidence suggests a dichotomy in the dysplasia-CIS-invasive carcinoma sequence in the pancreas. Pancreatic intraepithelial neoplasms (PanINs; small, incidental duct lesions) progress to invasive ductal adenocarcinomas (5-y survival of $<15 \%$ ), whereas intraductal papillary mucinous neoplasms (large, intraductal tumors with ductal dilatation) are often associated with colloid carcinoma (5-y survival of $>55 \%$ ). We explored the relationship of these lesions by examining the expression of MUC1 and MUC2, glycoproteins reportedly reflecting "aggressive" and "indolent" phenotypes in pancreas cancer, respectively. Immunohistochemical labeling with MUC1 (clone Ma695) and MUC2 (clone Ccp58) antibodies was performed on PanINs $(n=43)$, intraductal papillary mucinous neoplasms $(n=74)$, ductal adenocarcinomas $(n=$ 136), and colloid carcinomas $(n=15)$. Fifty-four percent of the intraductal papillary mucinous neoplasms expressed MUC2, whereas none of the PanINs did. In contrast, PanINs, especially higher grade lesions, were often positive for MUC1 $(61 \%$ of PanIN $3)$, whereas the expression of this glycoprotein was infrequent in intraductal papillary mucinous neoplasms (20\%). This dichotomy was further accentuated in the invasive carcinomas with which these two preinvasive pathways are respectively associ-

Copyright () 2002 by The United States and Canadian Academy of Pathology, Inc.

VOL. 15, NO. 10, P. 1087, 2002 Printed in the U.S.A.

Date of acceptance: June 21, 2002.

Supported in part by the National Cancer Institute Specialized Program in Research Excellence (SPORE), Grant P50-CAG2924.

Address reprint requests to: N. Volkan Adsay, M.D., Harper Hospital and Wayne State University, 3990 John R. Street, Detroit, MI 48201; e-mail: adsayv@med.wayne.edu; fax: 313-745-9299.

DOI: $10.1097 / 01 . M P .0000028647 .98725 .8 B$ ated: all colloid carcinomas were MUC2+ (100\%) and $\mathrm{MUC1}-(0 \%)$, whereas the labeling pattern was the reverse for ductal adenocarcinomas: $63 \%$ were MUC1 + and only $1 \%$ were MUC2+. These results support a dichotomy in the dysplasia-CIS sequence in the pancreas. Because these two pathways often lead to different types of invasive carcinomas, this is an invaluable model for the study of carcinogenesis. The findings here also support the previous impression that MUC2 (the mucin associated with gel formation) is a marker of the "indolent" pathway (intraductal papillary mucinous neoplasm and colloid carcinoma), whereas MUC1 (the glycoprotein known to have an inhibitory role in cell-cell and cell-stroma interactions as well as in immunoresistance of tumor cells) is a marker of the "aggressive" pathway (PanIN to ductal adenocarcinoma).

KEY WORDS: Carcinogenesis, Carcinoma, Dysplasia, Immunohistochemistry, Intraductal, Intraepithelial, Mucin, MUC1, MUC2, Neoplasm, Pancreas. Mod Pathol 2002;15(10):1087-1095

The vast majority of pancreatic neoplasms are ductal adenocarcinomas, characterized morphologically by invasive tubular units that are often associated with a dense desmoplastic stroma. Ductal adenocarcinomas are among the most lethal cancers, with an overall 5-year patient survival rate of $<5 \%(1-3)$. As is true for other epithelial malignancies, ductal adenocarcinomas are believed to arise from morphologically distinct precursor lesions (412). A uniform nomenclature and standardized diagnostic criteria for these precursor lesions have recently been adopted, and the accepted terminology is now pancreatic intraepithelial neoplasia (PanIN; 13). 
A form of pancreatic neoplasia distinct from ductal adenocarcinoma has also recently been recognized. This type of pancreatic neoplasia forms papillary masses within the large ducts of the pancreas, giving rise to clinically detectable cystic change. These tumors had been previously reported under a variety of names, such as "villous adenoma" (14, 15), "intraductal papillary tumor" $(16,17)$, "mucinproducing tumor" $(18,19)$, "ductectatic mucinous cystic tumor" (20-22), and "mucinous duct ectasia," but have recently been unified under the heading intraductal papillary mucinous neoplasms (IPMNs; 2, 3, 23), the term that is also endorsed by the World Health Organization (3). IPMNs can be distinguished from the more widely recognized mucinous cystic neoplasms. The latter generally afflict younger women, tend to be located in the tail of the pancreas, and contain ovarian-like stroma (23-28).

In approximately $30 \%$ of patients with IPMN, there is an associated invasive carcinoma $(18,29-$ 37 . The invasive component may resemble ordinary ductal adenocarcinoma. However, more commonly, it is a distinctive mucinous type of invasive carcinoma referred to as mucinous noncystic, muconodular $(18,31,32,34)$, or colloid carcinoma (38, 39). Colloid carcinomas of the pancreas have an indolent clinical course. The 5-year survival rate of patients with resected colloid carcinoma, including those with lymph node metastasis and perineurial invasion, is $55 \%(38,39)$, significantly better than that of patients with resected conventional ductal adenocarcinoma, which is $<15 \%$.

The MUCs are a group of genes that transcribe for glycoproteins (mucins) that are differentially expressed in various tumor types (40-49). In fact, MUC1 (mammary-type mucin) and MUC2 (intestinal-type mucin) have been reported as markers of "aggressive" and "indolent" phenotypes in pancreas cancer, respectively $(41,43,44)$. MUC1 was found to have an inhibitory role in cell-cell and cell-stroma interaction, mostly through integrins, and it is also said to have a role in immunoresistance of neoplastic cells to cytotoxic T cells. MUC2, on the other hand, is associated with gel formation via polymers that are linked end to end by disulfide bonds. It may also have a role in regulation of cell proliferation via the cysteine-rich domains.

Emerging evidence suggests that IPMN and colloid (mucinous noncystic) carcinoma form a distinct pathway of carcinogenesis in the pancreas (38, 39) and that MUC2 may be the marker of this pathway (50). Furthermore, ordinary ductal carcinoma of the pancreas was found to lack expression of this marker but showed MUC1 expression instead (41, $43,44,50)$. There is, therefore, preliminary evidence of a dichotomy in pancreatic carcinogenesis. However, the expression of these markers in PanINs, the precursors of ductal adenocarcinoma, has not been documented. This study was undertaken to test the expression of these markers in a large number of cases of ductal adenocarcinoma, colloid carcinoma, IPMN, as well as in PanINs in an attempt to clarify the relationships among these entities.

\section{MATERIALS AND METHODS}

\section{Cases}

One-hundred thirty-six ordinary ductal adenocarcinomas, 15 colloid carcinomas, 74 IPMNs, and forty-three examples of PanIN were gathered from the files of the Karmanos Cancer Institute-Wayne State University, The Johns Hopkins Hospital, and Memorial Sloan-Kettering Cancer Center. Of the 74 IPMNs, 26 were either adenomas or borderline lesions, and 48 were carcinomas, as classified according to the World Health Organization criteria (3). Of those with intraductal papillary mucinous carcinoma, 33 had associated invasive carcinoma; only the in situ component of these cases was included for interpretation. Of the 43 PanINs, 30 were graded as PanIN 1 or 2, and 13 were graded as PanIN 3 according to the grading scheme adopted recently (13). Twenty-four of these PanINs originated from patients with ductal adenocarcinoma, and 19, from patients with no primary carcinoma in the pancreas. Representative sections from formalin-fixed and paraffin-embedded tissues were obtained, and 5 - $\mu \mathrm{m}$ sections were prepared on sialyated slides for immunolabeling.

\section{Immunohistochemical Stains}

The immunohistochemical stains were performed by the avidin-biotin peroxidase complex method. The commercial antibodies MUC-1 (clone Ma695) and MUC-2 (clone Ma695) and MUC-2 (clone Ccp58), along with the secondary antibody and detection kit, were purchased from Vector Laboratories (Burlingame, CA). After deparaffinization and blocking of endogenous peroxidase, tissue sections were steamed in $10 \mathrm{~mm}, \mathrm{pH} 6.0$, citrate buffer for 20 minutes and allowed to stand in the hot buffer for an additional 20 minutes. MUC1 and MUC2 antibodies, diluted 1:1000, were incubated with the tissue sections for 60 and 90 minutes, respectively. Biotinylated anti-mouse and avidinbiotin complex were applied for 10 minutes each. After color development with 3-amino-9ethylcarbazole, sections were counterstained with hematoxylin.

Benign and neoplastic breast and colon tissue were used as controls for MUC1 and MUC2 antibodies, respectively. 


\section{Evaluation of the Labeling}

The labeling of both antibodies was evaluated in each of three compartments: cytoplasmic, apicalmembranous, and luminal. Each compartment was scored both for the extent and the intensity of labeling. The extent was recorded semiquantitatively as the percentage of the cells that showed labeling: 0 for $<10 \%$ of the cells, focal for $10-50 \%$, and diffuse for $>50 \%$. The intensity was scored as negative (for no labeling), weak, and strong.

For the purpose of comparative analysis, labeling of any intensity in $>10 \%$ of the cells was considered to be expression.

\section{Statistical Analysis}

Pairwise comparisons were used between the preinvasive and invasive components of the presumed dichotomous pathways separately: PanIN 1 and 2 with IPM adenoma/borderline, PanIN 3 with IPM carcinoma, and ductal adenocarcinoma with colloid carcinoma. Fisher exact test was used for the comparisons in which some cells had an expected value of $<5 . \chi^{2}$ test was used for the remainder.

\section{RESULTS}

\section{Normal Tissue}

The controls labeled appropriately. In the normal pancreas, MUC1 was expressed in the intralobular small ductules (those in close proximity to the centroacinar area) that were lined by small, cuboidal cells with minimal cytoplasm. These served as internal controls. The labeling in these ductules was limited to the apical membrane, forming a thin, faint band. No intracytoplasmic labeling was seen. The interlobular ducts, acini, and islets were negative for MUC1. No MUC2 labeling was noted in the normal pancreas.

\section{Neoplastic Pancreas}

In most instances, when present, the labeling for these markers was substantial in a given case. This was especially true for MUC2. Eighty-four percent of the MUC2 expressors had diffuse and strong labeling. For MUC1, 46\% of the expressors had diffuse and strong labeling; in the remainder, it was focal but strong.

\section{MUC1}

Most ductal adenocarcinomas expressed MUC1 diffusely and strongly (80\% apical-membranous, $75 \%$ luminal-secretory, and $65 \%$ cytoplasmic), whereas expression was absent in all cytologic compartments of CCs $(P<.001)$. In general, the expression of MUC1 in IPMNs and PanINs was low, especially in the lower grade lesions: $<10 \%$ of the cases with PanINs 1-2 or IPM adenoma-borderline expressed this marker. However, the expression increased with increasing grade of dysplasia in both pathways; furthermore, there was a significant difference between the two pathways: MUC1 was expressed more frequently in PanIN $3(61 \%)$ than in IPM carcinoma in situ (20\%), $P=.01$.

\section{MUC2}

MUC2 was mostly expressed in the cytoplasm, with only negligible labeling in the apicalmembranous region. As expected, the labeling in the stromal and luminal mucin was negligible; this is known to be due to the alteration in the glycosylation pattern of the secreted MUC2 that renders it undetectable by the antibody. The cytoplasmic expression of MUC2 was significantly higher in colloid carcinomas $(15 / 15$ cases, $100 \%)$ than in ductal adenocarcinomas ( $1 / 136$ cases, $<1 \%), P<.0001$. There was a significant difference when comparing the cytoplasmic expression between IPMNs (54\% of the cases labeling with this marker) and PanINs (all negative), $P=.001$. There also appeared to be progressive increase in the expression of MUC2 from early IPMNs (adenoma and borderline) to higher grade IPMNs (carcinoma in situ) to colloid carcinomas: $30 \%, 54 \%$, and $100 \%$, respectively.

Further Analysis of MUC1 and MUC2 Expressors in Proposed Pathways

\section{PanIN-DA Pathway (Fig. 1): MUC1+, MUC2-}

Ductal Adenocarcinoma. Sixty-five percent of ductal adenocarcinomas were positive for MUC1, whereas MUC2 was detected in only 1/136 cases. This MUC2-positive ductal adenocarcinoma had significant intraluminal mucin formation as well as focal mucin extravasation and features overlapping between ductal adenocarcinoma and colloid carcinoma. Also, the tumor in this case was located near the ampulla.

PanIN. Although overall MUC1 expression was low in PanINs (including PanIN1, which is referred to as mucinous metaplasia/mucinous duct lesion), MUC1 expression in the higher grade lesions (PanIN3) was similar to that of ductal adenocarcinomas (61\% and 63\%, respectively). No MUC2 expression was detected in PanINs.

IPMN-Colloid Carcinoma Pathway (Fig. 2): MUC1-, MUC2+

Colloid Carcinoma. All 15 of 15 colloid carcinomas were positive for MUC2 and negative for MUC1.

IPMN. Overall MUC2 expression was $46 \%$, and in higher grade lesions (IPM carcinoma in situ), more than half expressed this marker. In addition, however, 12 cases of IPMNs (16\%) also expressed 

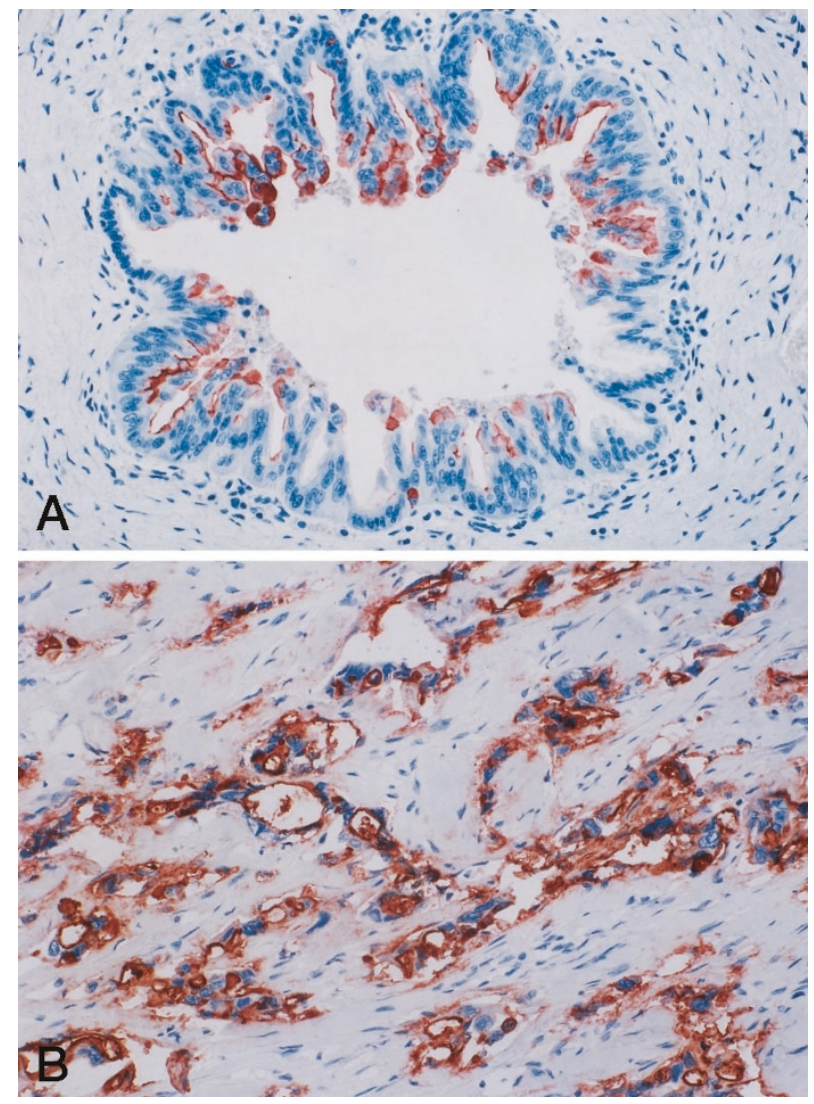

Figure 1. A, MUC1 in PanIN. Predominantly membranous and focally cytoplasmic MUC1 labeling in pancreatic intraepithelial neoplasm of grade 3. B, MUC1 in ductal adenocarcinoma. Strong cytoplasmic labeling of invasive tubular units is depicted.

MUC1. When these cases were reviewed, seven of them were found to have pancreatobiliary-type papillae, an uncommon subtype of IPMNs, seen in $20 \%$ of the cases; most IPMNs have gastric or intestinal phenotype $(23,51)$. More important, 6 of these 12 MUC1-positive IPMNs were associated with tubular-type invasion. The incidence of tubulartype invasion in MUC1-positive versus MUC1negative IPMNs was $50 \%$ and $16 \%$, respectively. MUC1 expression in the IPMN had a specificity of $90 \%$ for the presence of tubular type invasion (as opposed to colloid-type invasion) in the same case.

The expressions of the markers in different types of neoplasia in the three different cytologic compartments are summarized in Table 1 and Figure 3.

\section{DISCUSSION}

It is largely accepted that carcinogenesis in epithelial organs follows the hyperplasia-dysplasiaCIS-invasive carcinoma sequence. The preinvasive steps of this process have been identified in the pancreas as microscopic intraductal epithelial proliferations (4-12). The incidence of these lesions increase with age, and more atypical forms are much more frequently observed in patients with

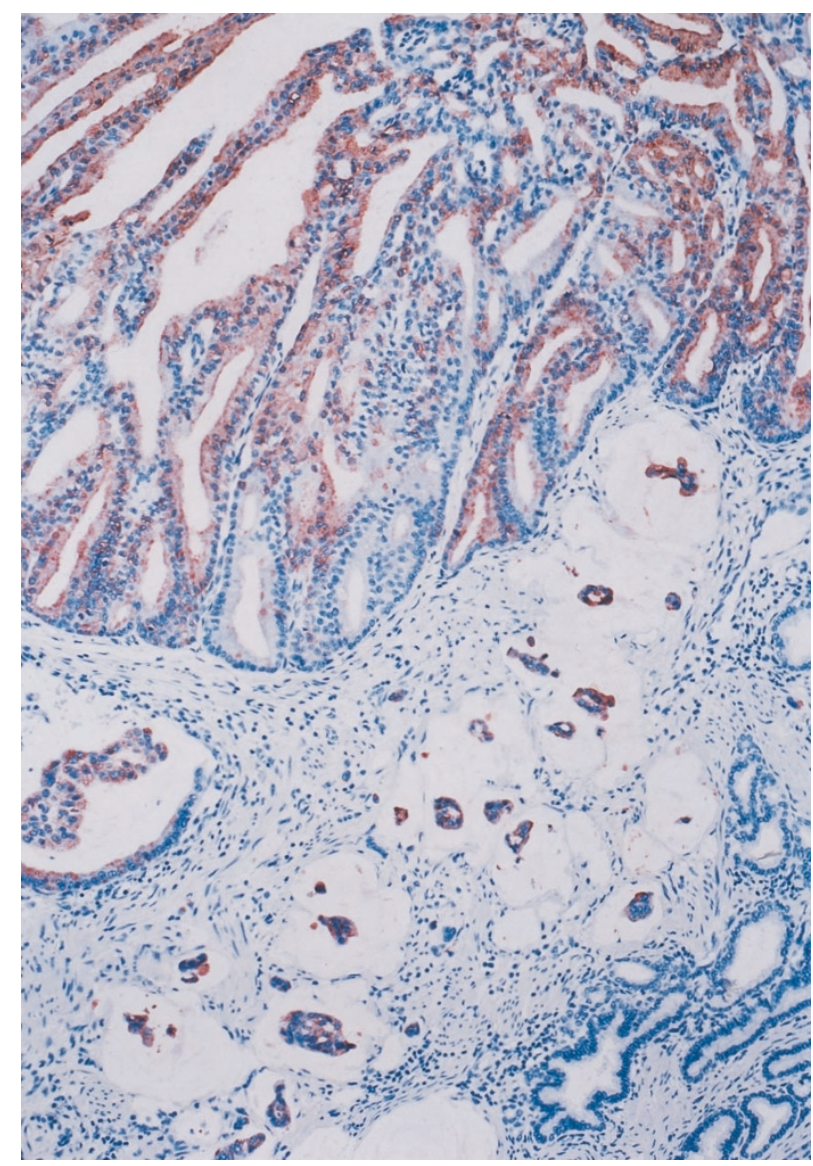

Figure 2. MUC2 in IPMN-colloid carcinoma pathway. Both the intraductal papillary mucinous neoplasm and colloid carcinoma (characterized by well delineated mucin lakes containing scanty detached carcinoma cells) show intracytoplasmic labeling.

invasive ductal adenocarcinoma than they are in patients without a cancer (52). The morphologic characteristics of these lesions parallel the dysplasia-CIS progression model in other organ systems. These observations suggest that these proliferations represent precursors of invasive ductal adenocarcinoma in the pancreas. This is also strongly supported by the recent molecular studies. Various terms have been applied to these lesions, including hyperplasia, atypical hyperplasia, dysplasia, and duct lesion, among others $(4-7,12,53,54)$. Recently, a new terminology analogous to those used in other organ systems has been adopted: pancreatic intraepithelial neoplasms (PanIN; 13).

In addition to these microscopic forms of dysplasia, there are larger, grossly identifiable massforming forms of intraductal preinvasive neoplasia that have been recently unified under the category of IPMNs. These probably represent the pancreatic counterpart of a distinct pathway of carcinogenesis that is seen in other epithelial organs and that is characterized by large papillary fronds forming clinically detectable intraluminal masses. The prototypical example of this phenomenon is papillary 
TABLE 1. Expressions of the Markers in Different Types of Neoplasia in the Three Different Cytologic Compartments

\begin{tabular}{|c|c|c|c|c|c|c|c|c|c|c|}
\hline & \multicolumn{4}{|c|}{ PanIN } & \multirow{2}{*}{$\begin{array}{c}\text { Ductal } \\
\text { Adenoca }\end{array}$} & \multicolumn{4}{|c|}{ IPMN } & \multirow{2}{*}{$\begin{array}{c}\text { Colloid } \\
\text { Ca }\end{array}$} \\
\hline & 1 & 2 & 3 & Overall & & Ad & Bor & $\mathrm{Ca}$ & Overall & \\
\hline \multicolumn{11}{|l|}{ MUC1 } \\
\hline Cy & $0 / 11$ & $3 / 17$ & $8 / 13$ & $11 / 43$ & $86 / 136$ & $0 / 11$ & $2 / 15$ & $10 / 48$ & $12 / 74$ & $0 / 15$ \\
\hline $\mathrm{Me}$ & $0 / 11$ & $2 / 17$ & $0 / 13$ & $2 / 43$ & $99 / 136$ & $1 / 11$ & $2 / 15$ & $16 / 48$ & $19 / 74$ & $0 / 15$ \\
\hline $\mathrm{Lu}$ & $0 / 11$ & $2 / 17$ & $0 / 13$ & $2 / 43$ & $105 / 136$ & $0 / 11$ & $1 / 15$ & $14 / 48$ & $15 / 74$ & $0 / 15$ \\
\hline \multicolumn{11}{|c|}{ MUC2 } \\
\hline Cy & $0 / 11$ & $0 / 17$ & $0 / 13$ & $0 / 43$ & $1 / 136$ & $0 / 11$ & $8 / 15$ & $26 / 48$ & $34 / 74$ & $15 / 15$ \\
\hline $\mathrm{Me}$ & $0 / 11$ & $0 / 17$ & $0 / 13$ & $0 / 43$ & $0 / 136$ & $0 / 11$ & $0 / 15$ & $0 / 48$ & $0 / 74$ & $0 / 15$ \\
\hline $\mathrm{Lu}$ & $0 / 11$ & $0 / 17$ & $0 / 13$ & $0 / 43$ & $0 / 136$ & $0 / 11$ & $4 / 15$ & $10 / 48$ & $4 / 74$ & - \\
\hline
\end{tabular}

PanIN, pancreatic intraepithelial neoplasia; IPMN, intraductal papillary mucinous neoplasms; Ad, adenoma; Bor, borderline; Ca, carcinoma; Cy, cytoplasmic; Me, membraneous/apical; Lu, luminal.

Numbers $(\mathrm{X} / \mathrm{Y})$, number of cases that expressed the marker in $>10 \%$ of the cells/number of cases examined.

\section{PREINVASIVE/ PRECURSOR}

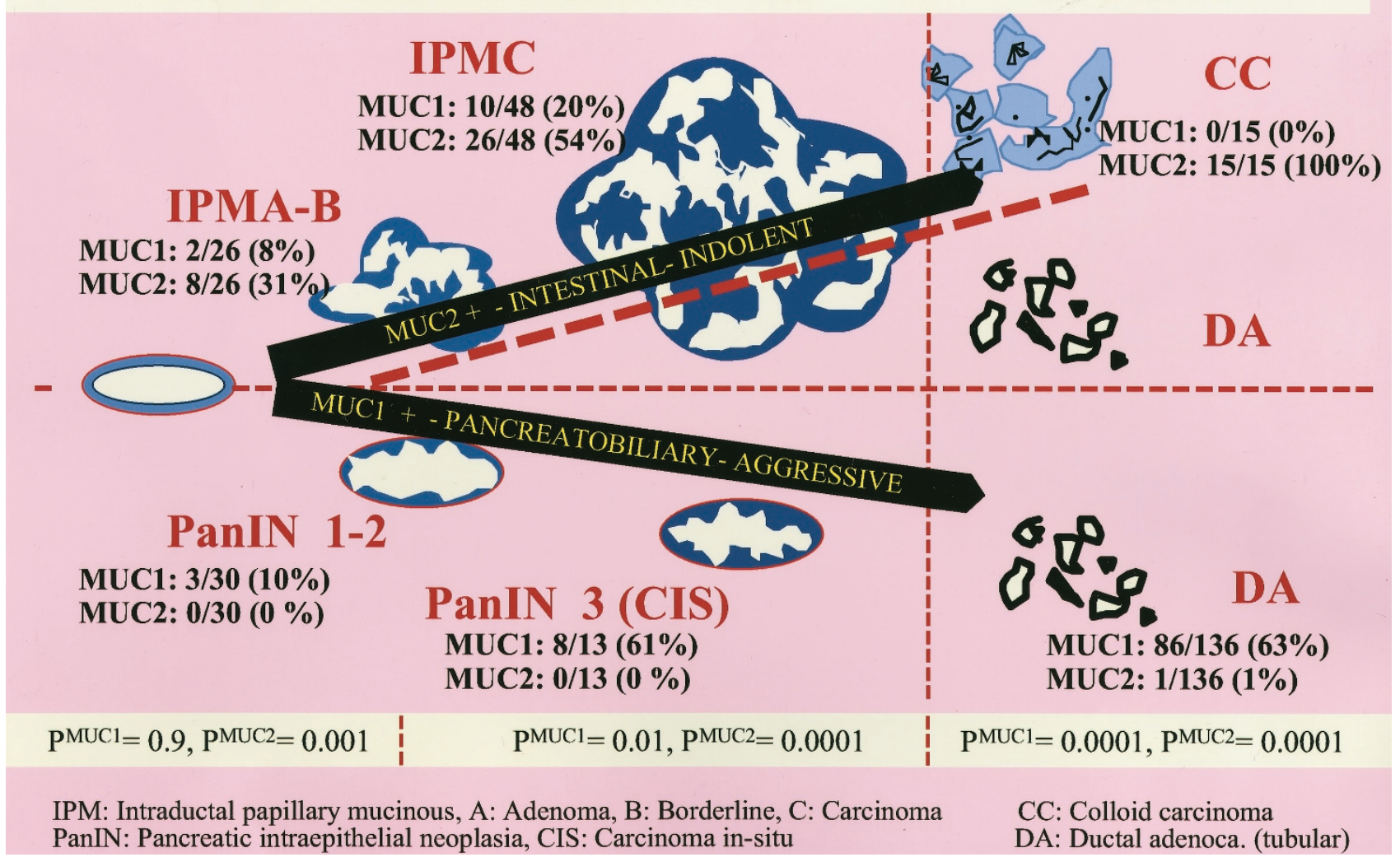

FIGURE 3. MUC2 in IPMN-colloid carcinoma pathway. Both the intraductal papillary mucinous neoplasm and colloid carcinoma (characterized by well-delineated mucin lakes containing scanty detached carcinoma cells) show intracytoplasmic labeling.

transitional cell carcinoma, which appears to be different from the microscopic "flat" precursors of invasive urothelial carcinoma, not only morphologically but also at the clinical and genetic levels (55).

IPMNs show various stages of dysplasia from adenoma to borderline to CIS and often exhibit a mixture of these grades within a given lesion $(2,3$, 23). Furthermore, $30 \%$ of IPMNs are associated with invasive carcinoma, and therefore, it is widely accepted that IPMNs are precursors of invasive carcinoma $(18,29-37)$. This conclusion is supported by recent molecular genetic observations (56). The invasive carcinomas that develop from IPMNs are either of the conventional ductal (tubular) type or the colloid (muconodular, mucinous noncystic) type (23). The association with colloid carcinoma is of special importance, because the biologic behavior of colloid carcinoma, with or without an identifiable IPMN component, is strikingly better than that of ductal adenocarcinoma. The 5-year survival rate of patients with resected colloid carcinoma is $>55 \%$ (as opposed to $<15 \%$ for those with ductal adenocarcinoma); even those patients with locally advanced tumors (lymph node metastasis or perineurial invasion) may live many years $(38,39)$. Furthermore, there is preliminary evidence that the molecular pathogenesis of colloid carcinoma 
may be different from that of ductal adenocarcinoma (38).

The hypothesis put forth here is that IPMN progressing to colloid carcinoma versus PanIN progressing to ductal adenocarcinoma form two separate pathways of carcinogenesis (see Fig. 3). This hypothesis is based on the distinct morphologic and clinical characteristics of these lesions discussed above. IPMNs progress to form large papillary nodules and maintain their growth intraluminally, often leading to marked cystic dilatation of the ducts that, in turn, allows $70 \%$ of them to become clinically detectable before they invade into the stroma. In addition, in many instances, the IPMN pathway progresses to a colloid-type invasive carcinoma, an indolent form of invasive carcinoma, instead of ductal adenocarcinoma. By contrast, PanINs remain clinically quiescent and progress to a much more aggressive form of cancer, ductal adenocarcinoma.

In this study, the expression of MUC1 and MUC2, mucin (glycoprotein) antigens $(40,41,43,44)$ was investigated in these proposed pathways. It had been previously documented in various organ systems that significant alterations in mucin chemistry take place during neoplastic transformation of secretory epithelial tissue (57-61). In the pancreas, dysplasia is often associated with a change to acidic sialomucin, which can be demonstrated by mucin histochemical stains $(62,63)$. Immunohistochemistry, however, is a more powerful tool in recognizing subgroups of different mucins. Recently developed antibodies for MUC1 (mammary-type mucin) and MUC2 (the intestinal/goblet type) have been used to detect differential mucin expression in pancreatic neoplasia (40-49). MUC1 is a membranous glycoprotein that has an inhibitory role in cell-cell and cell-stroma interaction, mainly through its reaction with integrins. Also, MUC1 has been found to have a role in immunoresistance of the tumor cells to cytotoxic T cells. MUC2, on the other hand, is a glycoprotein that is associated with gel formation through disulfide bonds.

The results in this study of MUC expression in ductal adenocarcinoma, colloid carcinoma, and IPMN are in accordance with those that have been reported in the literature (41-50). In addition, this study provides further evidence for the existence of a dichotomy in pancreatic neoplasia by demonstrating opposite patterns of MUC expression in PanIN-ductal adenocarcinoma versus IPMN-colloid carcinoma pathways.

Fifty-four percent of the IPMNs were found to express MUC2, whereas none of the PanINs labeled with this marker. In contrast, MUC1 expression was detected in $61 \%$ of high-grade PanINs (PanINs 3) and in only $20 \%$ of high-grade IPMNs (IPM carcinomas in situ). This dichotomy was further accen- tuated with regard to the invasive carcinomas with which these two pathways are respectively associated: colloid carcinomas were exclusively MUC2+ $(100 \%)$ and MUC1 - $(0)$, whereas $60 \%$ of DAs expressed MUC1, and only 1\%, MUC2. In most instances, when expressed, these glycoproteins were present in a substantial number of cells. Almost half of the MUC1 expressors and $>80 \%$ of MUC2 expressors had diffuse positivity ( $>50 \%$ of the cells). Furthermore, even in cases with focal positivity, the intensity was strong.

Thus, the differential expression of MUC1 and MUC2 documented in this study supports the hypothesis that there are two distinct pathways of carcinogenesis in the pancreas: (1) PanIN progressing to infiltrating ductal adenocarcinoma and (2) IPMN progressing to colloid carcinoma. Of note, the studies by Kimura et al. (64), performed on small cystic lesions of the pancreas, lend interesting insight to this hypothesis. In their study of 300 autopsies with small cystic lesions in the pancreas, these authors found that invasive carcinoma was present almost exclusively in the cysts that measured 5-8 $\mathrm{mm}$ but not in those that were larger or smaller. Based on these findings, it can be postulated that the PanIN pathway tends to progress to invasion before it reaches a significant (clinically detectable) size, as depicted in the lower arm of Figure 3. IPMNs, on the other hand, continue expanding within the lumen of the larger ducts and reach clinical detectability in most cases before they invade to the stroma (upper arm of Fig. 3). The differences between these two pathways appear to be even greater than merely their growth tendencies and propensity for invasion. More important, the IPMN pathway often leads to colloid-type invasive carcinoma, which has a significantly better prognosis than does the conventional ductal (tubular) carcinoma. Moreover, early evidence suggests that even the ductal-type invasive carcinomas arising from IPMNs may have a different biology and a more protracted clinical course than those that arise from PanINs (35). The differences in the MUC1 and MUC2 expression in these two pathways add further support to this dichotomy.

What appears to distort an almost perfect mirror image expression are those few IPMNs that expressed MUC1 (20\%, 12 cases). In fact, this outlier group is likely to shed important light on the mechanisms of this dichotomy. When these cases were further analyzed, 7 of them (58\%) were found to have pancreatobiliary-type papillae, seen in only $20 \%$ of IPMNs; most IPMNs have gastric or intestinal phenotype $(23,51)$. This suggests that the morphologic appearance of the intraductal component (pancreatobiliary versus intestinal) may correlate with the type and the aggressiveness of the invasive component. More important, 6 of these 12 MUC1- 
positive IPMNs were associated with tubular-type invasion. The incidence of tubular-type invasion in MUC1-positive versus MUC1-negative IPMNs was $50 \%$ and $16 \%$, respectively $(P=.009)$. Furthermore, MUC1 expression in the IPMN was a good predictor of the type of invasion associated with the same case, with a specificity of $90 \%$ for tubular type over colloid type. These findings suggest that the IPMNs that express MUC1 may form a biologically distinct subgroup of this entity. This subgroup appears to be closer to the PanIN-ductal adenocarcinoma pathway.

Based on these findings, one can conclude that the IPMN-colloid carcinoma pathway can also be regarded as the MUC2-intestinal pathway with an indolent behavior. By contrast, PanIN-ductal adenocarcinoma is associated with MUC1-pancreatobiliary pathway, which is biologically aggressive. One of the main questions, then, is whether the MUC1 and MUC2 expression in these two pathways is simply an epiphenomenon or is one of the determinants for the preferential progression of an intraductal neoplastic cell towards one of these pathways. Because MUC1 has an inhibitory role in the cell-cell and cell-stroma interaction as well as in immune recognition of the neoplastic cells by cytotoxic $\mathrm{T}$ cells, it is conceivable that it has a role in progression of the neoplastic cells to ductal-type invasion. Ductal adenocarcinoma is infamous for rapid dissemination despite its often welldifferentiated appearance. It long has been suspected that intercellular and cell-stromal signaling pathways may have a role in the ease with which ductal adenocarcinoma cells spread. It is possible that MUC1 is a factor in this interaction. There is even stronger evidence for the role of MUC2 in the preferential progression of the intraductal neoplastic cells toward the opposite pathway. MUC2 is known to be the secretory-type mucin (43), released easily from the cell, and is responsible for gel formation via disulfide bond linkage. Colloid carcinoma has been referred to in the past as "gelatinous" carcinoma (65). It has long been suspected that the stromal mucin characteristic of colloid carcinoma in the exocrine organs acts as a containing factor, limiting the growth of the tumor and hence its indolent behavior $(38,66,67)$. Thus, MUC2 may have a role in the restricted growth of these tumors. This may also be the explanation of the relatively slow growth of those rare ductal adenocarcinomas that have abundant extracellular mucin reminiscent of colloid carcinoma. These cases are reported to be MUC2+ and MUC1-, placing them closer to colloid carcinoma than ductal adenocarcinoma (Klöeppel G, Lüttges J, personal communication, November 2000).

In conclusion, a dichotomy in carcinogenesis appears to exist in the pancreas in forms of PanINs versus IPMNs, which differ not only clinically, morphologically, and biologically but also immunophenotypically from each other. This has the potential to shed light on the mechanisms of neoplastic transformation. These two pathways are associated with different types of invasive carcinomas (ductal adenocarcinoma versus colloid carcinoma) with relative specificity. MUC1 and MUC2 may be key factors in the progression of intraductal cells towards one of these pathways. It is evident that further investigation into the molecular mechanisms of this dichotomy will be very informative in determining the mechanisms of carcinogenesis. Equally important will be identifying the reasons for the overlap and crossover areas.

Acknowledgments: The authors thank Pam Tabaczka, John Frank, and Glen Kotcher for their expertise in performing the immunohistochemical stains; Tierra Munn for organizing the data; and Cheryl Lubinski for her assistance in the preparation of the manuscript.

\section{REFERENCES}

1. Evans DB, Abruzzese JL, Rich TA. Cancer of the pancreas. In: Devita VT, Hellman S, Rosenberg SA, editors. Cancer: principles and practice of oncology. 5th ed. Philadelphia: Lippincott-Raven; 1997. p. 1144-234.

2. Solcia E, Capella C, Klöppel G. Tumors of the pancreas. Armed Forces Institute of Pathology atlas of tumor pathology. Vol. 20. Washington, D.C.: American Registry of Pathology; 1997. p. 53-64.

3. Klöppel G, Solcia E, Longnecker DS, Capella C, Sobin LH. World Health Organization international histologic classification of tumors. Vol. 2. Histologic typing of tumors of the exocrine pancreas. Geneva, Switzerland: Springer; 1996.

4. Sommers SC, Murphy SA, Warren S. Pancreatic duct hyperplasia and cancer. Gastroenterology 1954;27:629-40.

5. Klöppel G, Bommer G, Ruckert K, Seifert G. Intraductal proliferation in the pancreas and its relationship to human and experimental carcinogenesis. Virchows Arch 1980;387:22133.

6. Brat DJ, Lillemoe KD, Yeo CJ, Warfield PB, Hruban RH. Progression of pancreatic intraductal neoplasias to infiltrating adenocarcinoma of the pancreas. Am J Surg Pathol 1998; 22:163-9.

7. Furukawa T, Chiba R, Kobari M, Matsuno S, Nagura H, Takahashi T. Varying grades of epithelial atypia in the pancreatic ducts of humans. Classification based on morphometry and multivariate analysis and correlated with positive reactions of carcinoembryonic antigen. Arch Pathol Lab Med 1994;118:227-34.

8. Hruban RH, Wilentz RE, Kern SE. Genetic progression in the pancreatic ducts. Am J Pathol 2000;156:1821-5.

9. Longnecker DS. The quest for preneoplastic lesions in the pancreas. Arch Pathol Lab Med 1994;118:226.

10. Luttges J, Diederichs A, Menke MA, Vogel I, Kremer B, Klöppel G. Ductal lesions in patients with chronic pancreatitis show K-ras mutations in a frequency similar to that in the normal pancreas and lack nuclear immunoreactivity for p53. Cancer 2000;88:2495-504. 
11. Klimstra DS, Longnecker DS. K-ras mutations in pancreatic ductal proliferative lesions [letter; comment]. Am J Pathol 1994;145:1547-50.

12. Kozuka S, Sassa R, Taki T, Masamoto K, Nagasawa S, Saga S, et al. Relation of pancreatic duct hyperplasia to carcinoma. Cancer 1979;43:1418-28.

13. Hruban RH, Adsay NV, Albores-Saavedra J, Compton C, Garrett ES, Goodman SN, et al. Pancreatic intraepithelial neoplasia: a new nomenclature and classification system for pancreatic duct lesions. Am J Surg Pathol 2001;25:579-86.

14. Payan MJ, Xerri L, Moncada K, Bastid C, Agostini S, Sastre B, et al. Villous adenoma of the main pancreatic duct: a potentially malignant tumor? Am J Gastroenterol 1990;85:459-63.

15. Rogers PN, Seywright MM, Murray WR. Diffuse villous adenoma of the pancreatic duct. Pancreas 1987;2:727-30.

16. Morohoshi T, Kanda M, Asanuma K, Klöppel G. Intraductal papillary neoplasms of the pancreas. A clinicopathologic study of six patients. Cancer 1989;64:1329-35.

17. Kojima Y, Akiyama T, Saito H, Kosaka T, Kita I, Takashima S, et al. Multifocal intraductal papillary adenocarcinoma of the pancreas: report of a case. Surg Today 1993;23:471-5.

18. Yamada M, Kozuka S, Yamao K, Nakazawa S, Naitoh Y, Tsukamoto Y. Mucin-producing tumor of the pancreas. Cancer 1991;68:159-68.

19. Shimizu M, Manabe T. Mucin-producing pancreatic tumors: historical review of its nosological concept. Zentralbl Pathol 1994;140:211-23.

20. Itai Y, Ohhashi K, Nagai H, Murakami Y, Kokubo T, Makita K, et al. "Ductectatic" mucinous cystadenoma and cystadenocarcinoma of the pancreas. Radiology 1986;161:697-700.

21. Yanagisawa A, Ohashi K, Hori M, Takagi K, Kitagawa T, Sugano $\mathrm{H}$, et al. Ductectatic-type mucinous cystadenoma and cystadenocarcinoma of the human pancreas: a novel clinicopathological entity. Jpn J Cancer Res 1993;84:474-9.

22. Agostini S, Choux R, Payan MJ, Sastre B, Sahel J, Clement JP. Mucinous pancreatic duct ectasia in the body of the pancreas. Radiology 1989;170:815-6.

23. Adsay NV, Longnecker DS, Klimstra DS. Pancreatic tumors with cystic dilatation of the ducts: intraductal papillary mucinous neoplasm and intraductal oncocytic papillary neoplasms. Semin Diagn Pathol 2000;17:16-31.

24. Adsay NV, Klimstra DS, Compton CC. Cystic lesions of the pancreas. Semin Diagn Pathol 2000;17:1-6.

25. Thompson LDR, Becker RC, Pryzgodski RM, Adair CF, Heffess C. Mucinous cystic neoplasm (mucinous cystadenocarcinoma of low malignant potential) of the pancreas: a clinicopathologic study of 130 cases. Am J Surg Pathol 1999;23: $1-16$.

26. Wilentz RE, Albores-Saavedra J, Hruban RH. Mucinous cystic neoplasms of the pancreas. Semin Diagn Pathol 2000;17: 31-43.

27. Zamboni G, Scarpa A, Bogina G, Iacono C, Bassi C, Talamini $\mathrm{G}$, et al. Mucinous cystic tumors of the pancreas: clinicopathological features, prognosis, and relationship to other mucinous cystic tumors. Am J Surg Pathol 1999;23:410-22.

28. Klöppel G. Clinicopathologic view of intraductal papillarymucinous tumor of the pancreas. Hepatogastroenterology 1998;45:1981-5.

29. Azar C, Van de Stadt J, Rickaert F, Deviere M, Baize M, Klöppel G, et al. Intraductal papillary mucinous tumours of the pancreas. Clinical and therapeutic issues in 32 patients. Gut 1996;39:457-64.

30. Cellier C, Cuillerier E, Palazzo L, Rickaert F, Flejou JF, Napoleon B, et al. Intraductal papillary and mucinous tumors of the pancreas: accuracy of preoperative computed tomography, endoscopic retrograde pancreatography and endoscopic ultrasonography, and long-term outcome in a large surgical series. Gastrointest Endosc 1998;47:42-9.
31. Fukishima N, Mukai K, Kanai Y, Hasabe T, Shimada K, Ozaki $\mathrm{H}$, et al. Intraductal papillary tumors and mucinous cystic tumors of the pancreas: clinicopathologic study of 38 cases. Hum Pathol 1997;28:1010-7.

32. Nagai E, Ueki T, Chijiiwa K, Tanaka M, Tsuneyoshi M. Intraductal papillary mucinous neoplasms of the pancreas associated with so-called "mucinous ductal ectasia." Histochemical and immunohistochemical analysis of 29 cases. Am J Surg Pathol 1995;19:576-89.

33. Sessa F, Solcia E, Capella C, Bonato M, Scarpa A, Zamboni G, et al. Intraductal papillary-mucinous tumours represent a distinct group of pancreatic neoplasms: an investigation of tumour cell differentiation and K-ras, p53 and c-erbB-2 abnormalities in 26 patients. Virchows Arch 1994;425:357-67.

34. Loftus EV Jr, Olivares-Pakzad BA, Batts KP, Adkins MC, Stephens DH, Sarr MG, et al. Intraductal papillary-mucinous tumors of the pancreas: clinicopathologic features, outcome, and nomenclature. Members of the Pancreas Clinic, and Pancreatic Surgeons of Mayo Clinic. Gastroenterology 1996; 110:1909-18.

35. Adsay V, Conlon K, Brennan MF, Klimstra DS. Intraductal papillary mucinous neoplasms: a clinicopathologic study of in-situ and invasive carcinomas associated with 28 cases. Cancer 2002;94:62-77.

36. Yamao K, Ohashi K, Nakamura T, Suzuki T, Shimizu Y, Nakamura Y, et al. The prognosis of intraductal papillary mucinous tumors of the pancreas. Hepatogastroenterology 2000;47:1129-34.

37. Cuillerier E, Cellier C, Palazzo L, Deviere J, Wind P, Rickaert $\mathrm{F}$, et al. Outcome after surgical resection of intraductal papillary and mucinous tumors of the pancreas. Am J Gastroenterol 2000;95:441-5.

38. Adsay NV, Pierson C, Sarkar F, Abrams J, Weaver D, Conlon $\mathrm{KC}$, et al. Colloid (mucinous noncystic) carcinoma of the pancreas. Am J Surg Pathol 2001;25:26-42.

39. Siedel G, Iacobuzio-Donahue C, Sohn TA, Adsay NV, Yeo CJ, Lillemoe K, et al. Almost all infiltrating colloid carcinomas of the pancreas and periampullary region arise from in-situ papillary neoplasms: a study of 33 cases. Am J Surg Pathol 2002;26:56-63.

40. Luttges J, Brocker V, Kremer B, Klöppel G. Immunohistochemical mucin expression and DPC4 status in intraductal papillary mucinous tumors (IPMTs) of the pancreas [abstract]. Pancreas 2000;21:459.

41. Yonezawa S, Taira M, Osako M, Kubo M, Tanaka S, Sakoda K, et al. MUC-1 mucin expression in invasive areas of intraductal papillary mucinous tumors of the pancreas [letter]. Pathol Int 1998;48:319-22.

42. Yonezawa S, Horinouchi M, Osako M, Kubo M, Takao S, Arimura $\mathrm{Y}$, et al. Gene expression of gastric type mucin (MUC5AC) in pancreatic tumors: its relationship with the biological behavior of the tumor. Pathol Int 1999;49:45-54.

43. Yonezawa S, Sato E. Expression of mucin antigens in human cancers and its relationship with malignancy potential. Pathol Int 1997;47:813-30.

44. Yonezawa S, Sueyoshi K, Nomoto M, Kitamura H, Nagata K, Arimura Y, et al. MUC2 gene expression is found in noninvasive tumors but not in invasive tumors of the pancreas and liver: its close relationship with prognosis of the patients. Hum Pathol 1997;28:344-52.

45. Osako M, Yonezawa S, Siddiki B, Huang J, Ho JJ, Kim YS, et al. Immunohistochemical study of mucin carbohydrates and core proteins in human pancreatic tumors. Cancer 1993; 71:2191-9.

46. Yonezawa S, Byrd JC, Dahiya R, Ho JJ, Gum JR, Griffiths B, et al. Differential mucin gene expression in human pancreatic and colon cancer cells. Biochem J 1991;276:599-605.

47. Yuan M. Histological localization of mucin core polypeptide MUC-2 in application to the differential diagnosis of adeno- 
carcinoma. Chung Hua Ping Li Hsueh Tsa Chih 1992;21:13941.

48. Hollingsworth MA, Strawhecker JM, Caffrey TC, Mack DR. Expression of MUC1, MUC2, MUC3 and MUC4 mucin mRNAs in human pancreatic and intestinal tumor cell lines. Int J Cancer 1994;57:198-203.

49. Balague C, Gambus G, Carrato C, Porchet N, Aubert JP, Kim YS, et al. Altered expression of MUC2, MUC4, and MUC5 mucin genes in pancreas tissues and cancer cell lines. Gastroenterology 1994;106:1054-61.

50. Luttges J, Zamboni G, Longnecker D, Klöppel G. The immunohistochemical mucin expression pattern distinguishes different types of intraductal papillary mucinous neoplasms of the pancreas and determines their relationship to mucinous noncystic carcinoma and ductal adenocarcinoma. Am J Surg Pathol 2001;25:942-8.

51. Merati K, Klimstra DS, Abrams J, Hruban RH, IacobuzioDonahue CD, Sarkar F, et al. Intraductal papillary mucinous neoplasms (IPMNs) of the pancreas exhibit three morphologically and immunophenotypically distinct epithelium [abstract]. Mod Pathol 2001;14:200A.

52. Andea A, Munn T, Sarkar F, Cheng JD, Adsay NV. A comparative analysis of pancreatic intraepithelial neoplasia (PanIN) in malignant and benign pancreata [abstract]. Mod Pathol 2002;15:282A.

53. Brockie E, Anand A, Albores-Saavedra J. Progression of atypical ductal hyperplasia/carcinoma in situ of the pancreas to invasive adenocarcinoma. Ann Diagn Pathol 1998;2:286-92.

54. Volkholz H, Stolte M, Becker V. Epithelial dysplasias in chronic pancreatitis. Virchows Archiv A Pathol Anat Histol 1982;396:331-49.

55. Grignon D. Neoplasms of the urinary bladder. In: Bostwick D, Eble J, editors. Urologic surgical pathology. St. Louis, MO: Mosby; 1996. p. 225-30.

56. Fujii H, Inagaki M, Kasai S, Miyokawa N, Tokusashi Y, Gabrielson E, et al. Genetic progression and heterogeneity in intraductal papillary-mucinous neoplasms of the pancreas. Am J Pathol 1997;151:1447-54.
57. Gloor E, Hurlimann J. Cervical intraepithelial glandular neoplasia (adenocarcinoma in situ and glandular dysplasia). A correlative study of 23 cases with histologic grading, histochemical analysis of mucins, and immunohistochemical determination of the affinity for four lectins. Cancer 1986;58: 1272-80.

58. Griffioen G, Bosman FT, Verspaget HW, de Bruin PA, Biemond I, Lamers CB. Mucin profiles and potential for malignancy of human colorectal adenomatous polyps. Cancer 1989;63:1587-91.

59. Agawa S, Jass JR. Sialic acid histochemistry and the adenoma-carcinoma sequence in colorectum. J Clin Pathol 1990;43:527-32.

60. Peuchmaur M, Potet F, Goldfain D. Mucin histochemistry of the columnar epithelium of the oesophagus (Barrett's oesophagus): a prospective biopsy study. J Clin Pathol 1984;37: 607-10.

61. Lapertosa G, Baracchini P, Fulcheri E. Mucin histochemical analysis in the interpretation of Barrett's esophagus. Results of a multicenter study. The Operative Group for the Study of Esophageal Precancer. Am J Clin Pathol 1992;98:61-6.

62. Yamao K, Nakazawa S, Fujimoto M, Tsuda H, Matsumoto K, Iwase T. A mucous histochemical and immunohistochemical study of precancerous and neoplastic lesions in the human pancreas. Int J Pancreatol 1993;14:37-44.

63. Xerri L, Payan MJ, Choux R, Gros N, Figarella-Branger D, Sarles H. Predominance of sialomucin secretion in malignant and premalignant pancreatic lesions. Hum Pathol 1990; 21:927-31.

64. Kimura W, Nagai H, Kuroda A, Muto T, Esaki Y. Analysis of small cystic lesions of the pancreas. Int J Pancreatol 1995; 18:197-206.

65. Ende VV, Riniker P. Gelatinous carcinoma of the appendix. Schweiz Med Wochenschr 1969;99:716-8.

66. Jacobson J, Ying L, Hoda S. Pure mammary mucinous carcinoma: an invasive or a non-invasive neoplasm [abstract]? Mod Pathol 1998;11:11A.

67. Rosai J. Ackerman's surgical pathology. Vol 2. St. Louis: Mosby, 1996. p. 1607-9. 